Espacio, Tiempo y Forma, Serie IV, Historia Moderna, t. 17, 2004, págs. 143-162

\title{
De la conspiración austracista a la integración a la nueva planta: La familia Duran, máximo exponente de la burguesía mercantil en el siglo XVIII ${ }^{1}$
}

\author{
Gemma Garcia Fuertes \\ Universidad de Barcelona
}

\section{RESUMEN}

La Guerra de Sucesión constituye uno de los episodios que más han marcado la historia de Cataluña. Sin embargo, este interés aún no ha desvelado todos los interrogantes que suscita el giro dinástico de Cataluña en el año 1705. Entre los muchos puntos oscuros, es preciso avanzar en un mejor conocimiento de las causas que llevaron a los diferentes grupos de la sociedad catalana a su posición politica.

Así surgió la idea de un estudio monográfico sobre la familia Duran, la dinastía más importante de hombres de negocios de la Barcelona del siglo XVIII, no sólo por su posición austracista en la guerra de Sucesión, lo que les acarreó la confiscación de bienes por la autoridad felipista, sino por la rápida integración de

la nueva coyuntura generada por los

Borbones. En efecto, el camalecnismo político de esta familia perteneciente a la

burguesia mercantil, por otro lado nada excepcional, puede resultar ilusirativo para entender la posición de importantes sectores de la sociedad catalana durante la Guerra de Sucesión.

\section{ABSTRACT}

The War of Succession is one of the events that most deeply marked the history of Catalonia. However, this interest has not yet revealed all the questions concerning the dinastic shift of Catalonia in 1705. Among other oscure aspects, it is necessary to reach a better knowledge about the reasons that led the different groups of Catalan society to their political position.

In this context, the idea arouse to study the Duran familly, the most important dinasty of businessmen in eighteenthcentury Catalonia, not only by his Austracist position in the War of Succession --what brought them the confiscation of all their properties by Philip $V$ 's authorities-, but also by their quick integration in the new situation created by the Bourbon Monarchy. In fact, the chamaleon-like political behaviour of this merchant family -othenwise not unusual - can illustrate the political position of important groups of Catalan society during the War of Sucession.

1 Una primera version sin notas de este artículo apareció en C. Martínez Shaw (ed.): Historia Moderna. Historia en construcción, Lérida, vol. II, 1999, pp. 513-527. 
La Guerra de Sucesión constituye uno de los episodios que más han marcado la historia de Cataluña. De ahí que haya despertado el interés de muchos investigadores, no sólo en el pasado por parte de la historiografía romántica, sino también entre las nuevas generaciones que han venido realizando importantes contribuciones en los últimos años. Sin embargo, este interés, que bien puede equipararse con la trascendencia de la contienda bélica, aún no ha desvelado todos los interrogantes que suscita el giro dinástico de Cataluña en el año $1705^{2}$.

Entre los muchos puntos oscuros, es preciso avanzar en un mejor conocimiento de las causas que llevaron a los diferentes estratos de la sociedad catalana a su posición política. En efecto, la configuración de un partido austracista en el Principado, claramente antiborbónico, en el que influyó más el apoyo de las diferentes capas de la sociedad catalana a un proyecto político y económico encarnado por el archiduque Carlos que una supuesta lealtad dinástica, sigue suscitando muchos interrogantes.

Joaquim Albareda planteaba la necesidad de avanzar realizando diferentes trabajos, entre los que destacaba la conveniencia de la elaboración de monografías sobre hombres de negocios del período, una línea de análisis muy fructífera, especialmente cuando la burguesía mercantil, mayoritariamente concentrada en Barcelona, constituyó, según el mismo autor, el alma del partido austracista ${ }^{3}$.

Compartiendo esta opinión surgió la idea de un estudio monográfico sobre la familia Duran, la dinastía más importante de hombres de negocios del siglo XVIII, no sólo por su posición austracista en la guerra de Sucesión, lo que les acarreó la confiscación de bienes por la autoridad filipista, sino por su rápida integración en la nueva coyuntura política generada por los Borbones.

En efecto, el camaleonismo político de esta familia perteneciente a la burguesía mercantil, por otro lado nada excepcional, puede resultar ilustrativo para entender la posición política de importantes sectores de la sociedad catalana durante la Guerra de Sucesión. Una postura que vino determinada más por la inclusión de los intereses económicos de la ascendente burguesía mercantil en el proyecto político austracista, que no por la mera lealtad dinástica, aunque esta se encubriera

2 La relación bibliográfica siguiente no pretende ser exhaustiva, sino solamente recoger las obras claves para el estudio del periodo: M. Bruguera: Historia del memorable sitio y bloqueo de Barcelona y la heroica defensa de los fueros y privilegios de Cataluña de 1713 y 1714, vols. I y II, Barcelona, 1871-1872; S. Sanpere i Miquel: El fin de la nación catalana, Barcelona, 1905; F. Soldevilla.: "Catalunya en la Guerra de Successió", Recerques i Comentaris, núm. 1 (1929), pp. 11-18; J. M. Torras i Ribé: "Reflexions sobre l'actitud dels pobles i estaments catalans durant la Guerra de Successió", Pedralbes, núm. 1 (1981), pp. 187-209; A. Porta i Berguedà, La victòria catalana de 1705, Barcelona, 1984; J. Albareda i Salvadó, Els catalans i Felip V, de la conspiració a la revolta (1700-1705), Barcelona, 1993; J. M. Torras i Ribé: La Guerra de Successió i els setges de Barcelona (1697-1714), Barcelona, 1999; J. Albareda i Salvadó: La Guerra de Succesió il' Onze de Setembre, Barcelona, 2000; R. M. Alabrús: Felip V i l'opinió dels catalans, Lérida, 2001; J. Fontana: "La guerra de Successió i les Constitucions de Catalunya: una proposta interpretativa», y E. Lluch: “El programa polític de la Catalunya austracista», en VV.AA.: Del patriotisme al catalanisme, Vic, 2001.

3 J. Albareda i Salvador, «Repensar la Guerra de Succesió a Catalunya (1705-1714)", L'Avenç, núm. 206 (1996), pp. 17-45. 
en la defensa del orden constitucional que representaba la monarquía pactista encarnada por los Austrias.

La falta de entusiasmo y el temor de las autoridades catalanas a adherirse al Archiduque en el desembarco aliado dirigido por Darmstadt, en julio de 1704, contrastan con su decidida actuación un año más tarde. El giro dinástico de 1705, a pesar de las interesantes investigaciones de Joaquim Albareda, sigue despertando no pocos interrogantes, y sólo nuevos análisis pueden ser capaces de explicar lo que ocurrió realmente entre 1701 y 1705 . De ahí que siga vigente la reflexión de Nuria Sales al señalar que "a part de la propaganda i dels desembarcaments, no sabem què devia pasar perquè es produís el perjuri. De motius de recel envers Lluis XVI, els Borbons de França, en sobraven, però ja abans de 1701. De contrafac-cions, tant per part del nou rei com per part dels seus virreis, se'en produïren moltes, però cap d'elles no sembla novetat d'aquell regnat "4.

La trayectoria familiar de la dinastía Duran sólo puede ser explicada, pues, respondiendo a algunos de los interrogantes planteados, especialmente por su imbricación en los acontecimientos que condujeron a los hombres de comercio de Barcelona a apostar decididamente por el bando austracista y a constituirse en el motor de su partido.

Los Duran encarnaron perfectamente a esta ascendente burguesia comercial barcelonesa, cuyo éxito económico crecía al amparo de la coyuntura alcista de la Cataluña del último cuarto de siglo XVII, un período fructífero en proyectos económicos, materializados en diferentes obras, entre las que cabe destacar el Fénix de Catalunya de Narcís Feliu de la Penya de $1683^{5}$.

Una burguesía mercantil deslumbrada por el modelo político y comercial de Holanda, cuyos intereses económicos se orientaban progresivamente hacia la fachada atlántica. Un comercio vehiculado, especialmente a través del puerto de Lisboa, desde donde llegaban a Barcelona productos coloniales como el tabaco y el azúcar, mientras que los productos catalanes exportados se centraban casi exclusivamente en el aguardiente y frutos secos, es decir, productos agrícolas excedentarios, consecuencia de la recuperación del campo catalán en estas fecha. El aguardiente se convirtió, ya a finales del siglo XVII, en el primer producto exportador, y Lisboa en el destino principal, centro consumidor y exportador hacia Ámsterdam y Londres ${ }^{6}$. 413.

${ }^{4}$ N. Sales, "Guerra de Successió (1705-1712)", Història de Catalunya, Barcelona, vol. IV, pp. $412-$

5 N. Feliu de la Penya, Fénix de Cataluña, compendio de sus antiguas grandezas, y medio para renovarlas, Barcelona, 1683. Sobre la personalidad, obra y coyuntura económica de la época del autor, $P$. Vilar, Catalunya dins de l' Espanya Moderna, vol. II, Barcelona, 1964; P. Molas i Ribalta, Comerç i estructura social a Catalunya i Valencia als segles XvII $i$ xVII, Barcelona, 1977, pp. 70-141. Del mismo autor, "A tres-cents anys del Fénix de Catalunya. Recuperació i reformisme econòmic sota Carles $\|$ ", Pe. dralbes, núm. 3 (1983), pp. 147-174: y H. Kamen: La España de Carlos II, Barcelona, 1981, pp. 133-139.

6 C. Martinez Shaw, Cataluña en la Carrera de Indias, 1680-1756, Barcelona, 1981, pp. $72-79$. 
Los hombres de comercio concentrados en Barcelona aparecían desde 1680 más ligados económicamente a Portugal, Holanda y Gran Bretaña que no a Francia, cuyos paños, además, invadirían los mercados catalanes arruinando la tradicional draperia. De ahí que la recuperación de este sector constituyera uno de los grandes objetivos propuestos por Narcís Feliu de la Penya en su Político Discurso de $1681^{7}$.

Francia fue para la menestralía textil catalana el principal competidor. Por ello, la política mercantilista propuesta por Feliu de la Penya para proteger «les robes catalanes" difícilmente era viable con la entronización de un Borbón. Si a estos intereses contrapuestos añadimos los de la burguesía mercantil ascendente, cuyos negocios se vieron paralizados por el inicio de la Guerra de Sucesión, podemos entender la inclusión de ambos sectores sociales en el partido austracista y su sintonía con los primeros focos de rebeldía. Por otra parte, en la Plana de Vic habia crecido un fuerte espíritu antifrancés como consecuencia de los agravios sufridos a manos de las tropas de Luis XIV, a lo que se unia la intensa adhesión que la figura del virrey Darmstadt despertaba entre amplios sectores de la población a causa del prestigio adquirido en las guerras contra Francia y determinante de su protagonismo en los desembarcos aliados ${ }^{8}$.

Será precisamente esta confluencia de intereses los que dará lugar a la conspiración fracasada de 1704 y al giro dinástico de 1705, fecha en que se produjo la materialización de los objetivos, no siempre coincidentes, de tres sectores perjudicados por la llegada de un Borbón al trono de España: una burguesía que vio cómo sus antiguos mercados del Atlántico Norte le eran vetados al pertenecer a potencias enemigas; una menestralía invadida por productos franceses; y los dirigentes vigatans entre los que creció el espíritu antifrancés. Ellos fueron los detonantes de un movimiento amplio que se extendió por diversas comarcas de Cataluña: Plana de Vic, el epicentro de la revuelta; el Camp de Tarragona, fuertemente ligado a los intereses mercantiles de Barcelona como proveedor de frutos secos y aguardiente destinados al Atlántico Norte (puerto de Salou), pero también Segarra y Urgell, zonas castigadas por las campañas bélicas entre Francia y España a finales del siglo XVII, y la Marina, cuyo desarrollo se veía favorecido por la descentralización del despegue económico del Principado.

La incompatibilidad de estos sectores analizados con la monarquía de Felipe $\mathrm{V}$, explica el giro dinástico de los catalanes en 1705, a pesar de que parte del programa económico de Narcís Feliu de la Penya se concretase en las Cortes de Felipe V, en 1701-1702, y con posterioridad, se ratificase en las convocadas por Carlos $1 \mathrm{II}^{9}$. El perjurio tuvo su antecedente más inmediato en la conspiración fracasada

7 P. Molas i Ribalta, Comerç..., pp. 95-107.

8 J. Albareda, Els catalans..., pp. 20-50.

9 Coincidimos con Núria Sales cuando afirma que «l'any 1700, o l'any 1705-1706, no eren l'alternativa d'autonomia-perdua de libertats ni la d'absolutisme-pactisme que estaven en joc. Per tant, els catalans que continuaven fidels al primer Borbó (recordem que Catalunya l'havia jurat per rei en corts solemníssimes) no necessàriament ho feien per menyspreu a aquelles llibertats" (N. Sales, Senyors, 
de 1704, cuyos participantes protagonizaron el Pacto de Génova de 1705, precedente del desembarco aliado y de la adhesión de las autoridades catalanas al Archiduque, el futuro Carlos $1 I^{10}$.

La alianza de la burguesía mercantil con el proyecto político austracista es bien conocida, así como el protagonismo de algunos de sus miembros más destacados, como la familia Feliu de la Penya ${ }^{11}$. Sin embargo, la implicación de los Duran no ha sido suficientemente analizada, primero por falta de datos sobre su trayectoria política durante la contienda y, en segundo lugar, por el desconocimiento de las relaciones de parentesco entre los diferentes comerciantes apellidados Duran, por lo que sólo estamos informados de los negocios emprendidos por los distintos miembros de la familia de forma individualizada, y especialmente de su actuación después de la contienda bélica.

La inclusión de los Duran en el mundo de los grandes negocios generados en Barcelona, se inició con Antoni Pau Duran ${ }^{12}$, adroguer y ciudadano de Barcelona, casado con Emerenciana Mora, con la que tuvo nueve hijos, entre los que destacarian Josep y Vicenç Duran i Mora, el primero, el primogénito, mercader desde 1695, y el segundo, adroguer, los cuales fundaron una de las compañías comerciales más importantes de finales del siglo XVII, que sobrevivió al conflicto bélico.

Siguiendo la tradición familiar, los Duran iniciaron su actividad comercial a través de una droguería, que en aquella época era una tienda abierta al público donde se expedian drogas, azúcar, confituras, frutos secos, arroz, tabaco y especias, mayoritariamente. Sin embargo, como muchos miembros de la élite gremial de Barcelona, los Duran invertirán en otros sectores ${ }^{13}$.

bandolers, miquelets i botiflers, Barcelona, 1984, p. 143). Sobre las Cortes y su programa económico, cf. J. Bartrolí i Orpí, "La Cort de 1701-1702: un camí truncat», Recerques, núm. 9 (1979), pp. 57-75; y P Voltes Bou, "Las Cortes tenidas en Barcelona por el Archiduque Carlos de Austria en 1705-1706, Boletín de la Real Academia de Buenas Letras de Barcelona, núm. 28 (1959-69), pp. 69-81.

${ }^{10}$ El pacto de Génova aparece transcrito en Record de Aliança fet al Serm. Jordi-Augusto, Rey de la Gran Bretaña. Biblioteca de Catalunya, Fullets Bonsoms, núm. 834. Sobre los pormenores del desembarco aliado de 1704, asi como los preliminares del pacto de Génova, cf. A. Porta, La victòria..., pp. 197262 y $293-309$

${ }^{1}$ En esta línea sigue siendo imprescindibie $\mathrm{P}$. Vilar, Le "Manual de la Compañya Nova" de Gibraltar. 1709-1723, París, 1962, pp. 9-14.

12 Las noticias que tenemos sobre su actividad mercantil son dispersas, pero suficientes para corroborar la afirmación anterior. Así, en 1665 aparece relacionado con Pedro Bensi y Gorgollón, ciudadano honrado de la colonia genovesa en la ciudad. (Cf. J. C. Maixé Altés, Comercio y banca en la Cataluña del siglo xvili. La Compañia Bensi \& Merizano de Barcelona (1724-1750), La Coruña, 1994, p. 26). Las relaciones de los Duran con la colonia genovesa de Barcelona se mantendrán en la siguiente generación, como tendremos oportunidad de anaiizar. Posteriormente, le vemos integrando la compañía "Domingo Mora y Antoni Pau Duran", que operó entre 1675 y 1690, quince años en que la sociedad se renovó en dos ocasiones. La primera sociedad contaba con un fondo social de 18.500 libras y la segunda de 20.353, constituyendo su base uria botiga de tejidos. Evidentemente, el parentesco de Antoni Pau Duran con Domingo Mora, su cuñado, explica su inclusión como socio en la misma, en la que Domingo Mora figura como mercader, título obtenido en 1670 que le situaba en la cúspide de la jerarquía mercantil. (Cf. 1. Lobato Franco, Compañias y negocios en la Catalunya preindustrial, Sevilla, 1995, p. 96.)

13 I. Lobato, Compañias..., pp. 114-118. 
Josep y Vicenç Duran formarán parte de la élite mercantil de Barcelona desde la constitución, en 1699, de una sociedad comercial bajo el nombre de «Joan Pau Llorens, Josep Duran y Compañía". Se trata de la sociedad mercantil más importante de las estudiadas por Isabel Lobato en la Barcelona del siglo XVII, si atendemos al capital social. Compañía destinada a todo tipo de negocios, es decir, sin ninguna especificidad, a la que Josep Duran aporta 16.500 libras como socio capitalista y que llega a completar, mediante otras aportaciones, un capital inicial de 60.500 libras.

Aunque esta compañía debía prolongar su actividad hasta 1704 , su administrador, Joan Pau Llorens convocó, en 1701, a sus socios con el objeto de retirar parte del capital existente en la sociedad. Las causas que se alegaron fueron, inicialmente, las altas ganancias obtenidas en las diferentes operaciones realizadas $(40 \%)$, pero también influyeron en la decisión las escasas expectativas comerciales futuras, que eran consecuencia, según rezaba el informe del propio administrador, de la paralización del comercio, estancamiento de precios y falta de circulante.

Entre los argumentos esgrimidos por el administrador Llorens en su informe, destaca que de "mantenintse la pau (que Deu conserve), encara se aniran disminuhint més los negocis" ${ }^{14}$. Sin duda, esta interesante afirmación refleja el estado de ánimo de algunos sectores de la burguesia mercantil barcelonesa, que veian en la paz una de las causas del marasmo económico. Una paz que bien pudo truncarse mediante la decidida participación de la burguesía mercantil a favor del Archiduque.

Los hermanos Josep y Vicenç Duran también extendieron sus negocios primero hacia el comercio colonial vía Cádiz y, después de 1705, a través del puerto de Lisboa ${ }^{15}$. Se interesaron, posteriormente, en los negocios financieros, cuyos beneficios les permitieron participar en grandes operaciones, como el arrendamiento del estanco del tabaco entre 1704 y 1709 mediante la constitución de una compañía. Más tarde, aprovechando la coyuntura y las alianzas generadas por la contienda bélica, vemos la firma de Josep y Vicenç Duran como banqueros en diversas operaciones de la "Companyia Nova de Gibraltar", culminando así su trayectoria comercial, consecuencia de la recuperación del último cuarto del siglo XVII reforzada por las nuevas expectativas mercantiles generadas por la gue$\mathrm{rra}^{16}$.

Ambos hermanos, Josep y Vicenç Duran, pertenecían al mundo de los grandes negocios, desde finales del siglo XVII, y siguieron haciéndolo durante la contienda bélica, como hemos tenido ocasión de comprobar, por lo que podemos confirmar su perfecta inserción en el sector más pujante de la burguesía mercantil de Bar-

${ }^{14}$ I. Lobato, Compañias..., pp. 224 y 223-228.

15 C. Martinez Shaw, Cataluña..., p. 44 y nota 70.

16 I. Lobato Franco, Compañias..., pp. 117 y 195-200. 
celona, que constituyó el núcleo central inspirador del partido austracista. Una burguesia comercial que, representada por hombres como Narcís y Salvador Feliu de la Penya, veía en la guerra de 1705 un vehículo para convertir a Cataluña en otra Holanda, siguiendo la conocida expresión de Pierre Vilar ${ }^{17}$.

A pesar de que los hermanos Duran formaban parte de la élite del mundo de los negocios de Barcelona antes del estallido del conflicto, ello no les convertía forzosamente en integrantes del grupo conspirador, es decir, en miembros destacados del partido austracista. Sin embargo, distintos datos apuntan a esta dirección como pretendemos demostrar.

El primer desembarco aliado de 1704 fue totalmente inoperante, al fracasar la trama interior descubierta por las autoridades borbónicas, trama en la que tuvieron un papel importante algunos eclesiásticos y el grupo de los vigatans, así como Antoni Peguera i Aimeric, quien desde Barcelona debia facilitar la apertura de sus puertas con el objeto de rendir la ciudad ante el ataque aliado. El control de la situación por parte del virrey Velasco, así como el temor de las autoridades catalanas a adherirse a la causa austracista, abortaron la conspiración.

Sin embargo, la aparente lealtad de los grupos dirigentes catalanes en esas fechas no impidió una dura represión por parte del virrey Velasco, lo que hace pensar que, o bien la conspiración había sido más amplia de lo que los datos nos permiten deducir, o bien que el comportamiento de las autoridades borbónicas acabó, finalmente, decantando los ánimos recelosos y ambiguos de 1704.

Entre las víctimas de la represión, vemos al Dr. Ramon Vilana Perlas, emparentado con los Dalmases; al Dr. Francesc Barata, rector de Premià, relacionado con la familia del comerciante Amador Dalmau; y al propio Narcís Feliu de la Penya, quien a partir de entonces entró en contacto con Darmstadt y el propio Antoni Peguera, al que aconsejó ponerse de acuerdo con los líderes rebeldes de la Plana de Vic, quienes debian propiciar el éxito del antiguo virrey y la toma de Barcelona $^{18}$.

La represión borbónica también alcanzó a la familia Duran. Así, un hermano de Josep y Vicenç Duran i Mora, el notario Francesc, miembro del Consell de Cent, fue encarcelado por no revelar las deliberaciones de este organismo, solicitadas

17 Este autor atribuia el giro dinástico de 1705 a los intereses de la burguesia mercantil, una burguesia que se veía deslumbrada por el modelo político y economico de Holanda (Cf. P. Vilar, Catalunya..., v. il, pp. 410-411 y 416; y, Le Manual..., p. 97, nota 5). También en J. Albareda y S. Sancho, "Catalunya el 1765: un informe econòmic i polític", Pedralbes, núm. 8-1 (1988), pp. 279-297.

18 A. Porta, La victòria..., p. 264. Para ia biografia de Ramon de Vilana Perlas, cf. E. Lluch, L'alternativa catalana (1700-1714-1740). Ramon de Vilana Perlas i Juan Amor de Soria: teoria i acció austracistes, Vic, 2000. Las relaciones de Francesc. Barata y la importante familia austracista Dalmau, así como su trayectoria política, en J. R. Carreras i Bulbena, Antoni de Villarroel, Rafel Casanova i Sebastià Dal. mau, heroichs defensors de Barcelona en lo siti de 1713-14, Barcelona, 1912, p. 69. Sobre la relación de Narcís Feliu de la Penya con la conspiración de 1704 y el pacto de Génova, cf. su obra, Anales de Catalunya, v. III, Barcelona, 1709, pp. 510-553. Los autores contemporáneos que han estudiado el tema, como A. Porta y J. Albareda en las obras ya citadas, siguen esta fuente directa, ya que el autor asume en primera persona su participación en estos hechos. 
por el virrey Velasco en sus pesquisas sobre la conspiración, compartiendo prisión con otros sospechosos de austracismo.

Una vez superados los treinta días en que concluía el término legal de la detención, la Junta constituida por el Consell de Cent envió un comisionado a Madrid, Pau Ignasi de Dalmases, acompañado de su cuñado, Josep Faust de Potau i Ferran, hijo del conde de Vallcabra. Una vez en la Corte fueron apresados por el alguacil del presidente del Consejo de Aragón, el duque de Montalto, y se les desterró a tierras castellanas, desconociéndose con exactitud el destino, aunque sabemos que Dalmases estaba en París en el momento que fue canjeado por prisioneros felipistas en $1709^{19}$.

La represión felipista continuaba, por lo que el partido austracista ganaba adeptos. De ahí que no sea gratuito que entre los austrófilos más fervientes durante la guerra veamos a la mayor parte de los represaliados por las autoridades borbónicas antes de 1705, lo que explica el cambio de actitud de amplios sectores de la sociedad del Principado, pasando de una conducta inicialmente expectante a otra resueltamente más decidida.

El golpe definitivo se producirá después de la firma del Pacto de Génova, suscrito, el 20 de junio de 1705, por dos exiliados, Antoni Peguera i Aimeric y el doctor Domènec Parera, de Vic, ambos con plenos poderes conferidos por un grupo de vigatans, quienes representaban en teoría al Principado, mientras que Mitford Crowe, plenipotenciario de la reina Ana de Inglaterra, materializaba la alianza anglo-catalana que desembocó en el desembarco aliado de octubre de 1705.

La escasa relevancia de las personas implicadas en el Pacto de Génova no concuerda con la trascendencia del mismo, por lo que tal vez detrás de esos hombres se ocultaban otros más importantes, pero más temerosos en caso de fracaso. De ahí que, aunque no aparezca ningún miembro de la burguesía comercial barcelonesa suscribiendo el acuerdo, pues la represión de Velasco en la ciudad lo impedía, todos los datos disponibles apuntan a que la firma de la alianza no fue ajena a sus intereses y objetivos.

Tampoco la elección de Génova como lugar de encuentro fue gratuita, ya que los Peguera estaban emparentados con los Berardo, importantes miembros de la colonia genovesa, aunque naturalizados catalanes, lo que tal vez puede explicar la elección de esta plaza comercial como punto de encuentro con Mitford Crowe. Una plaza donde, por otra parte, los comerciantes catalanes mantenían excelentes relaciones mercantiles ${ }^{20}$.

${ }^{19}$ F. Soldevila: "La presó de Pau Ignasi de Dalmases i Ros, enviat de la ciutat de Barcelona a Felip V (1705)", Homenatge a Antoni Rubió i Lluch, v. III, Barcelona, 1936, pp. 481-492.

20 Los Peguera habian emparentado con los Berardo a través del matrimonio de Lluís Peguera i Llaudes con una joven de esta familia. Los Berardo procedian de Florencia y Pisa y estaban emparentados con los Negroto de Génova. Francisco de Berardo fue un importante comerciante establecido desde la infancia en la ciudad, donde obtuvo el título de cavaller en 1622. Durante la guerra dels Segadors, Agustín Berardo, hijo de Pelegro Berardo, muy influyente en la colonia genovesa de la ciudad, fue expulsado 
Por otro lado, son bien conocidos los excelentes contactos de Antoni Peguera i Aimeric y su familia con el patriciado urbano de Barcelona, especialmente su relación con el círculo de amistades de Pau Ignasi Dalmases, ya que era asiduo a su casa de la calle Montcada, como miembro fundador de la Academia de los Desconfiados creada en el año $1700^{21}$. Por otra parte, diversas fuentes nos informan de la amistad de Mittord Crowe con el padre de Antoni, Guerau de Peguera i Berardo, cuando aquél residía como comerciante en Barcelona. Eran, asimismo, asiduos a los mismos círculos de sociabilidad, su socio y cónsul inglés Joseph Shallet, sin olvidar al cónsul holandés, Jan Kies y su compatriota, Arnold de Jäger, ambos expulsados de Cataluña antes de 1705. Todos ellos no sólo eran conocidos de Guerau, sino del príncipe de Darmstadt durante su estancia en Barcelona como virrey de Cataluña ${ }^{22}$.

Muchos de ellos compartían negocios mediante su inclusión en diferentes compañias. Sus intereses económicos comunes se veian reforzados por los lazos de parentesco que en muchos de los casos les vinculaban al patriciado urbano, ampliando sus horizontes sociales. Además, se veían cohesionados por la solidaridad que empezaba a despertar la dura represión de Velasco entre algunos de sus miembros más destacados. Por último, las expectativas de un conflicto bélico auspiciaban lucrativos negocios. ¿Realmente, se necesitaba más para apostar decididamente por el Archiduque?

a Génova por las autoridades francesas, como también su pariente, Lluis de Peguera, abuelo del signatario del pacto de Génova. Tampoco debemos olvidar que Antoni Peguera no sólo era nieto de una Berardo, sino también cuñado de María Berardo i Morera, casada con su hermano Josep. No es tampoco casual que la joven fuese hija de un importante austracista, Francesc de Berardo i Espuny, marqués de Montnegre, título concedido por el Archiduque, embajador ante la corte austriaca en 1713 y más tarde exiliado en Viena. Todo ello apunta a considerar la elección de Génova como un lugar seguro para la firma del pacto anglo-catalán, no sólo por la neutralidad de la República durante la guerra, sino por los lazos de parentesco de Antoni Peguera con la familia Berardo. Sobre los Berardo de Barcelona, cf. J. C. Maixé Altés, "La colonia genovesa en Cataluña en los siglos XVII y XVill: los Bensi", Actes del Primer Congrés d' História Moderna de Catalunya, Barcelona, 1984, vol. I, pp. 523-532. Sobre la trayectoria política del marqués de Montnegre, cf. A. Porta, La victòria..., pp. 288-299, 424, 433 y 524. Prueba de las excelentes relaciones comerciales con esta plaza es la nómina de corresponsales extranjeros de las firmas mercantiles de Barcelona en 1716: de los 444 declarados, 72 son de Génova, lo que supone más del 18 $\%$ del total. Independientemente del tiempo en que estos corresponsales habian establecido relaciones con los citados comerciantes, su alto porcentaje parece indicar que los vinculos eran anteriores, en muchos casos, a la guerra de Sucesión (cf. J. M. Torras i Ribé, "Els corresponsals del comerç català amb Europa al començament del segle xvilı,. Recerques. núm. 23 (1979), pp. 115-139.

¿' Sobre la actividad económica de Pau Dalmases, cf. I. Lobato, "Societats mercantils a la Barcelona del segle XVII. La companyia Dalmases-Ferrer", Estudis d'História Económica, Palma de Mallorca, 1988-I, pp. 27-44. Para una aproximación a la activiciad política de Pau Ignasi de Dalmases, cf. P. Voltes Bou, "Nuevas noticias de D. Pablo Ignasi de Dalmases y Ros y su tiempo", Boletín de la Real Academia de las Buenas Letras, núm. 26 (1954-1956), pp. 95-136. La actividad de la Academia de los Desconfiados, en A. Ccmas, Historia de la literatura catalana, v. IV, Barcelona, 1965, pp. 77-86. Igualmente, en J. S. Amelang, La formación de una clase dirigente: Barcelona 1490-1714, Barcelona, 1986, pp. 166174.

22 A. Porta, La victòria..., pp. 112-113. No podemos de dejar de mencionar la sesión extraordinaria que los académicos desconfiados dedicaron al virrey de Cataluña en el año 1700. (Cl. E. Galindo Blasco y G. García Fuertes, "La Academia de los Desconfiados y el príncipe de Darmstadt. El diálogo emblemático de la Academia Cuarta. 22 de julio de 1700", Cuadernos de Arte e Iconografía, v. VI, núm. 11 (1993), pp. 455-467. 
La participación de Narcís Feliu de la Penya en la conspiración de 1705 es bien conocida, así como sus contactos con Vic a través de su socio, el botiguer de teles Martí Piles ${ }^{23}$. Sin embargo, son menos conocidos los contactos, así como los lazos de parentesco, de los Duran, quienes establecieron una tupida red que les vinculó a una serie de familias pujantes en determinadas localidades y que, como ocurrió con los Feliu de la Penya, reproducirá la geografía de los primeros focos austracistas en Cataluña.

Los Duran se beneficiarán del círculo de relaciones de la familia Feliu de la Penya, gracias a la relación de parentesco de ambas dinastías con la familia Isern, de Vilassar, en el Maresme, desde 1699, lo que explica su participación conjunta en algunos negocios ${ }^{24}$. Así, un estudio detallado de las redes económicas establecidas por la Compañía de Gibraltar revela que ésta se basó en las relaciones de parentesco de su socio y administrador, Salvador Feliu de la Penya. Un claro ejemplo de la plurifuncionalidad de las relaciones familiares en las sociedades preindustriales ${ }^{25}$.

Los Duran estaban relacionados con la Plana de Vic a través de sus lazos de parentesco con los Parrella de Torelló, antes de la guerra de Sucesión y, después de la contienda, con los Espona de Saderra ${ }^{26}$, ambas ligadas a las iniciativas económicas de la zona ${ }^{27}$. Uno de sus miembros más destacados, el $\mathrm{Dr}$. Fortià $\mathrm{Pa}$ rrella, formará parte en 1705 del Consejo Real del Archiduque ${ }^{28}$.

Las relaciones de parentesco establecidas por la familia Duran en 1699, especialmente a través del hijo primogénito de Josep, Jaume Duran i Pujades, constituirán una de las estrategias utilizadas para mantener una serie de contactos con

23 J. Albareda, Els catalans..., pp. 18-19.

24 Agradezco esta información a Benet Oliva i Ricós, estudioso de esta localidad, y que en la actualidad está elaborando un estudio sobre los fabricantes de algodón en el siglo xIx en la comarca del Maresme. Sabemos que la hija pequeña del cavaller Pere Isern, de Vilassar de Mar, Eulàlia Isern i Parrella, contrajo matrimonio en 1699 con Jaume Duran i Pujades, hijo primogénito de Josep Duran i Mora y su primera esposa, Maria Pujades, hija de Joan Pujades, payés de Sabadell. La sobrina de Eulàlia Isern i Parrella, Maria Coll i Isern, contrajo matrimonio ese mismo año con Salvador Feliu de la Penya, mercader y socio principal de la Companyia Nova de Gibraltar, en la que la sociedad de Josep y Vicenç Duran i Mora actuaron como banqueros. Pere Isern dotó a su hija con 600 doblas de oro, asi como con dos baúles nupciales; asimismo Josep Duran donó a su hijo 1.500 doblas de oro sobre su inversión de 3.000 doblas en la compañía Llorens-Duran (1699-1704), además de las masías Llobet y Bitlloc en Santa Perpètua de la Moguda. AHPB, not. Francesc Duran, I Man. Cap. Matrim., 27 de febrero de 1699, fols. 99-104.

${ }^{25}$ Esta conclusión se extrae al analizar la genealogía de los Feliu de la Penya y de los socios y agentes que intervinieron en la Companyia de Gibraltar, de la que íue administrador Salvador Feliu de la Penya.

26 Los vínculos de la familia Duran con la Plana de Vic se concretarán con el matrimonio de la nieta de Josep Duran i Mora, Eulàlia Duran i Isern, con el ciudadano honrado de Barcelona Jaume Espona, de Saderra, pueblo del actual municipio de Orís, pero fronterizo a Torelló, lo que demuestra que los contactos con esta zona prosiguieron después de la Guerra de Sucesión. Juame Espona obtuvo el título de caballero del Principado en 1775, (Cf. A. Fluvià Escorsa, aĺndice de cargos y empleos del Antiguo Ayuntamiento de Barcelona", Documentos y Estudios, v. III (1964), pp. 187-306.

27 Pocas noticias tenemos sobre la familia Parrella. Sabemos que sus miembros eran, en sus orígenes, paraires de Torelló y que además participaron en la roturación de tierras, constituyendo una de las familias más importantes de la localidad. De ahi que una vez enriquecidos se establecieran en Barcelona. A priricipios del siglo XVIII emparentaron con los Feliu de la Penya.

${ }^{28} \mathrm{~J}$. Albareda, Els catalans..., p. 19. 
las áreas favorecidas por la recuperación de Cataluña en la década de los ochenta del Seiscientos: Sabadell, Torelló, Vilassar de Mar y Mataró.

Finalmente, los Duran establecieron relaciones con el Baix Camp de Tarragona mediante la firma de Joan Pau Liorens y Cía creada en 1699. La sociedad, que ya hemos tenido ocasión de analizar, montó su comercio de exportación sobre la base del aguardiente de la zona, que no se dirigía, como ha señalado Carlos Martínez Shaw, a Cádiz y Lisboa, sino a Ámsterdam. Las pipas procedian de Reus, Montbrió y Riudoms, localidades donde un grupo de intermediarios 0 industriales se ocupaban, por encargo de la firma, de hacer fabricar aguardiente. La compañia contaba entre sus asociados con el reusense Jaume Domènec, que trabajaba de modo habitual con Josep Toda de Riudoms, quien, entre otros, preparaba las pipas para ser embarcadas en el puerto de Salou ${ }^{29}$.

También el aguardiente de la zona habia sido objeto del interés de la firma inglesa constituida por Joseph Shallet, cónsul británico, y Mitford Crowe, signatario del Pacto de Génova, cuyas actividades, documentadas desde 1693, aparecen vinculadas con la exportación de aquel producto desde el Camp de Tarragona, donde Shallet tenia algunas destilerías. Es ésta, pues, una firma comercial que no interrumpirá su actividad comercial tras el estallido de la guerra, sino que seguirá operando a través de la conocida Compañía de Gibraltar, en la que Salvador Feliu de la Penya figura como su más ferviente socio y en la que también participarán los hermanos Josep y Vicenç Duran, como ya se ha señalado ${ }^{30}$.

Estos datos nos evidencian las estrechas relaciones existentes entre el signatario del pacto de Génova e importantes miembros de la burguesía mercantil barcelonesa. Relaciones que se materializaron en su pertenencia a los mismo círculos sociales y comerciales y que, finalmente, les hizo confluir en la misma opción política.

Los deseos, las expectativas y la orientación económica de la ascendente burguesía barcelonesa explican su clara postura política, especialmente cuando

\footnotetext{
${ }^{29}$ La localidad de Riudoms, donde los Duran mantenian relaciones comerciales antes del estallido de la guerra, será uno de los focos pioneros a favor del giro dinástico, especialmente por los vínculos entre sus familias más pujantes y la burguesía barcelonesa, como ocurrirá también con la localidad de Reus. Así Josep Toda, el intermediario de la firma citada, era padre del conocido jurista austrófilo Francesc Toda i Gil, abogado del Consell de Cent, represaliado antes de 1705 y que será recompensado por el Archiduque con el título de caballero, ingresando en la Real Audiencia, de la que será regente. En $1737 \mathrm{fi}$ gura en el catastro de Riudoms como propietario de destilerías de aguardientes, aunque conste como ciudadano honrado de Barcelona, donde actuará como agente de la compañia sucesora de aquella con la que había colaborado su padre, la sociedad Ignasi Llorens y Cía. Un claro ejemplo de supervivencia y continuidad familiar en los negocios antes y después de la guerra de Sucesión. Tampoco es gratuito que sea la familia Nebot de Riudoms la que, por su vinculación al ejército antes de la guerra, constituya la espoleta de la revuelta austracista en el Camp de Tarragona. Uno de sus miembros más destacados, Rafael Nebot, asciende a corone! durante la contienda, obteniendo el título de conde en 1713 y exiliándose posteriormente a Viena por su fuerte implicación en el bando austrófilo. Sobre la importación de aguardiente realizada por la sociedad Llorens-Duran, asi como sobre los Toda, cf. C. Martinez Shaw, Cataluña..., pp. 50-51 y 60-61. Para la familia Nebot de Riudoms, cf. A. Porta, La victória..., pp. 515-518.

30 C. Martinez Shaw, Cataluña..., pp. 49 y $57-58$.
} 
sus propios intereses económicos entraban en contradicción con las alianzas de Felipe $V$, mientras que el Archiduque y sus aliados no sólo suponían una continuidad en los negocios emprendidos con éxito hasta entonces, sino que hacian vislumbrar un esperanzador futuro. Poca importancia tenía, entonces, para esos hombres de comercio y caudal, la marginalidad de la economía catalana dentro de la fachada atlántica, lo que les convertía en meros exportadores de productos agrarios, es decir, les situaba en la periferia del gran comercio de la época, que era, en realidad, lo que representó el sucedáneo de Gibraltar respecto al puerto de Cádiz ${ }^{31}$. Tampoco pesaba en sus decisiones el interesado apoyo de la Gran Bretaña a la causa aliada, consecuencia de su lucha por los mercados coloniales americanos en su rivalidad con Francia, ya que las conspiraciones, así como las revueltas, no sólo se basan en realidades, sino en esperanzadoras apuestas, aunque éstas sólo sean quiméricas ${ }^{32}$.

Los Duran no vacilarán sobre cual será su opción en 1705, como tampoco los Feliu de la Penya, los Feu, los Dalmau o los Dalmases, entre muchos otros hombres del comercio. De ahí que su actitud a favor del giro dinástico seguramente fuese más activa de lo que la historiografía ha dejado entrever ${ }^{33}$.

En el testamento cerrado de Vicenç Duran i Mora redactado en 1711, se cita la existencia de otros dos anteriores que, lógicamente, quedaron invalidados; uno de ellos era un codicilo realizado en Génova a principios de $1706^{34}$. La presencia de Vicenç en esa ciudad, en unas fecha próximas al pacto anglo-catalán, nos permiten, como mínimo, preguntarnos qué hacía un miembro destacado de una de las familias más poderosas del comercio de Barcelona en aquella república y cuáles eran los peligros que le amenazaban como para redactar sus últimas voluntades.

Sabemos que Mitford Crowe había llegado a Génova a principios de abril de 1705 , a donde oficialmente se le destinó para negociar con las autoridades locales diferentes asuntos comerciales, lo que le permitió encubrir su verdadera misión, que era secreta. También distintas fuentes nos informan sobre sus primeras acciones en la República, como las entrevistas que mantuvo con los exiliados catalanes antes de la llegada de Antoni Peguera, quien en esas fechas se encontraba en Viena. De ahí que resulte plausible que Vicenç Duran fuese uno de ellos, especialmente cuando un miembro de su familia había sido encarcelado por Velasco, por lo que todos sus integrantes eran sospechosos de austrofilia ${ }^{35}$.

Apoyarían esta hipótesis las excelentes relaciones de los Duran con la colonia genovesa antes y después de la guerra de Sucesión. Seguramente no fue casua-

31 C. Martínez Shaw, Cataluña..., pp. 78-82

32 A. Porta habla de un informe que Mitford Crowe había elaborado a instancias de Sydney Godolphin, lord del Tesoro, informe donde "els arguments eren freds i calculats a favor d' Anglaterra" (A. Porta, La victòria..., p. 298.)

33 J. Albareda, "La Guerra de Successió a Catalunya. Un assaig interpretatiu", Revista de Catalunya, nuim. 49 (1991), pp. 63-64.

34 AHPB. Not. Francesc Duran, Lib. Test., 19 de agosto de 1711, fol. 297

35 A. Porta, La victòria..., pp. 303-309 
lidad que la casa familiar de Josep Duran i Mora, adquirida en 1731, hubiese pertenecido al hermano de Antoni Peguera, Josep, yerno del marqués de Montnegre, embajador catalán en la corte imperial en plena guerra, quien en esas fechas seguía exiliado en Viena ${ }^{36}$.

En el inventario post mortem de Josep Duran i Mora, de $1735^{37}$, figura una relación de deudores de la sociedad comercial existente en esos momentos, heredera de la firma Josep y Vicenç Duran, activa antes de la guerra de Sucesión. Entre los acreedores aparece el príncipe de Darmstadt, con una deuda de $1.017 \mathrm{li}$ bras y 10 sueldos; el doctor Josep Duran, con 368 libras, 10 sueldos; los holandeses Jan Kies y Arnold de Jäger con 2.040 libras, 10 sueldos y 7 dineros. En todos los casos, se trata de deudas contraídas antes del giro dinástico, ya que el doctor Josep Duran, uno de los primeros austracistas a las órdenes del archiduque Carlos, habia fallecido en Portugal en 1704. Por otro lado, el tantas veces citado príncipe de Darmstadt, último virrey de Cataluña en el reinado de Carlos II, y protagonista de los desembarcos aliados en 1704 y 1705, habia fallecido en esta última fecha. Finalmente, los holandeses naturalizados Kies y Jäger fueron expulsados de Cataluña durante el período borbónico, por pertenecer a una nación enemiga de España, antes de $1705^{38}$.

Estas operaciones llevadas a cabo por la firma Josep y Vicenç Duran antes de 1705 y cuyos beneficiarios propiciaron el giro dinástico del citado año, si bien sólo reflejan una relación puramente económica: dejan entrever, por la importancia de los personajes implicados, una cierta intencionalidad política. El clima represivo que se vivió desde 1704, así como la caída en desgracia de todos ellos, no podía favorecer la obtención de créditos, de ahí que esta operación, pueda interpretarse como reflejo de una cierta solidaridad, tal vez como el resultado de la confianza que aquéllos despertaban entre los Duran o, por lo menos, como signo de un marcado interés en el rumbo que pudieran tomar los acontecimientos políticos.

36 La familia Duran mantuvo relaciones con la colonia genovesa por lo menos desde mediados del siglo xviı. Así, Francisco Gorgollón, natural de Sporto en la ribera de Génova, se instaló al menos desde 1628 en Barcelona, donde estuvo en contacto con los hombres de negocios del momento, entre los que cabe destacar a Antoni Pau Duran, quien también mantendrá relaciones comerciales con Pedro Bensi, sobrino y heredero de la firma comercial del anterior. Las relaciones entre los Duran y la familia Bensi se mantendrán en tres generaciones posteriores. De ahi que tras la muerte de Rafael Bensi en 1723, cuando, dada la minoria de edad de su hijo, su viuda forme compañía con el corso Pedro Merizano, encontremos, entre los numerosos habitantes de Barcelona que hacia 1724 daban fe de los negocios de Merizano en la ciudad, Génova y Cagliari, al mercader Josep Duran i Mora. (J. C. Maixé, Comercio..., pp. 20-28). La casa de Josep Duran i Mora fue adquirida en esta fecha al hermano del signatario del pacto de Génova, Josep Peguera i Aimeric, quien actuaba como tutor de los bienes de sus hijos habidos en su primer matrimonio con la hija del marqués de Montnegre; de ahi que esta casa casi con toda seguridad perteneciese a su suegro, que estaba exiliado en Viena. El inmueble situado en la calle de Viladecols era la residencia de muchos miembros de la colonia genovesa, no sólo de los Berardo, sino también de los Negro, los Gorgollón, después los Bensi, y posiblemente el mismo Pedro Merizano.

37 AHPB. Not. Pau Mollar, De inventaris et actionibus, 1722-1743. Inventario de Josep Duran i Mora, 18 de septiembre de 1735, s.t.

38 Sobre la trayectoria política del doctor Josep Duran, cf. A. Porta, La victória..., pp. 208, 235-236. Las actividades comerciales de Kies y Jäger, en C. Martínez Shaw, Cataluña..., pp. 58-59; e I. Lobato Franco, Compañias..., pp. 175-179 y 187-195. 
La entrada de las tropas felipistas, dirigidas por el duque de Berwick, el 11 de septiembre de 1714, suponia el fin de la Guerra de Sucesión en Cataluña, pero también significaba la derrota de un proyecto político y económico que algunos miembros de la burguesía mercantil, como Salvador Feliu de la Penya, conseller segon de Barcelona, habían defendido hasta sus últimas consecuencias. La familia Duran también permaneció dentro de Barcelona contribuyendo a la defensa de la ciudad, especialmente durante el período en el cual la mayor parte de los antiguos austrófilos la habían abandonado, huyendo de los peligros del riguroso asedio.

La guerra, que se saldaba además con la muerte de Vicenç Duran i Mora, con toda seguridad como consecuencia del sitio de Barcelona, como lo prueba el hecho de que su testamento se leyera el 16 de agosto de 1714. Seguramente su defensa a ultranza de la ciudad en 1713-1714 tampoco fue ajena a la vinculación de su patrimonio al abastecimiento y destino final de Barcelona. La misma Audiencia de Cataluña en 1728 consideraba obvia la permanencia de la familia hasta el 11 de septiembre: “... sin duda (Vicenç Duran i Mora) se quedó como los demás de esta familia, y otros muchos hombres de negocios para el cobro de sus crecidos caudales, en la defensa que aquella Ciud. Hizo contra las Rs. Armas de V.M. perdiendo la vida... ${ }^{39}$.

La muerte de Vicenç Duran i Mora hizo que la firma comercial prosiguiera bajo el nombre de Josep Duran y Jaume Duran, padre e hijo respectivamente, sin que su pasado austracista parezca entorpecer sus crecientes negocios en el período borbónico, ni tan siquiera su ascenso social. Así, Josep Duran i Mora obtuvo el título de caballero del Principado en 1727 y, dos años más tarde, su sobrino e hijo de Vicenç Duran, Josep Duran i Sala, consiguió su elevación al mismo rango.

La promoción de los Duran bajo el reinado de Felipe $V$ constituye un ejemplo de las ventajas que estos hombres de negocios podían obtener colaborando con el nuevo régimen borbónico. La sociedad Josep y Jaume Duran se convirtió en la temprana fecha de 1717 en asentista de víveres del mismo ejército contra el que habían luchado ${ }^{40}$, constituyendo su vinculación a la Intendencia de Cataluña no sólo una parte importante de sus actividades mercantiles de posguerra, sino su principal activo para alcanzar el estamento nobiliario. Así lo prueban los tres avales que acompañaron la solicitud de nobleza de Josep Duran i Mora en 1726: la del intendente Andrés Pérez Bravo, la del tesorero general del ejército Miguel Zavala y Auñón y, por último, la de José Patiño, intendente general de Marina en esas fe-

39 AHN, Consejos, Privilegios de Nobleza, leg. 17.943, s.f.

40 La sociedad Josep y Jaume Duran habia concertado el 17 de diciembre de 1717 el libramiento a la Intendencia de 60.000 raciones al puerto franco; raciones que procedían de fuera de la ciudad y que estuvieron exentas de los derechos de entrada a la misma. Por cada ración cobraron 1 real y 15 maravedises, lo que supuso un volumen de negocio de 3.000 duros, de los cuales percibieron una tercera parte por anticipado (J. Mercader i Riba, Felip V i Catalunya, Barcelona, 1985, p. 204, nota 289.). También en esa época y en años posteriores los vemos como importadores de granos norteafricanos destinados al ejército (E. Martín Corrales, Comercio de Cataluña con el Mediterráneo musulmán s. Xvi-XVII: "el comercio con los enemigos de la fe", Barcelona, 2001, pp. 331-336). 
chas y hombre clave en la Cataluña de posguerra, quienes certificaron los favores realizados por Josep Duran al Real Servicio después del 11 de septiembre de 1714 , mediante préstamos sin interés y apoyando con su crédito otras operaciones económicas de la Intendencia ${ }^{41}$.

La simbiosis existente entre la Intendencia y los miembros de la familia Duran, proveedores del ejército en Cataluña, les convirtió en la élite cambiaria en las primera décadas del siglo XVIII, ya que su sociedad mercantil actuó prácticamente en solitario en las operaciones bancarias concertadas por esos años, hasta que en la década de los años treinta perdieron su liderazgo en la ciudad ${ }^{42}$.

Sin embargo, la reinserción de la familia Duran en la nueva política no se limitó sólo a sus actividades mercantiles con la Intendencia. Josep Duran i Sala consiguió ingresar en el aristocrático ayuntamiento de Barcelona, una vez obtenido el título de noble en 1739 y gracias a la adquisición de una de las pocas regidurias a juro de heredad enajenadas por la Corona en las capitales de corregimiento, por un precio de 76.000 reales de vellón y 1.750 más de media annata ${ }^{43}$. Este reconocimiento, producto de su solvencia económica, no fue ajeno a su matrimonio con Gertrudis Brassó i Serra, que le habia permitido emparentar con influyentes familias de botiflers ligadas a las más importantes instituciones borbónicas de Cataluña ${ }^{44}$.

El ennoblecimiento de los Duran, así como el ingreso de uno de sus miembros en el ayuntamiento de Barcelona, no les impidió proseguir conjuntamente en el mundo de los negocios, ya que la firma Josep y Jaume Duran, tal como demuestra la documentación notarial, es heredera de Josep y Vicenç Duran ${ }^{45}$. Por tanto, se debería cuestionar también, teniendo en cuenta todo lo expuesto más arriba, la afirmación, tan generalizada, de que la burguesía mercantil no tuvo participación en el gobierno de la ciudad ${ }^{46}$. Así, los Duran, atendiendo a su aportación al ganancial,

${ }^{41}$ AHN, Consejos, Privilegios de Nobleza, leg. 17.943, s.f.

42 J. C. Maixé Altés, Comercio..., p. 237.

${ }^{43}$ J. M. Torras i Ribé, Els municipis catalans a l'Antic Règim (1453-1808), Barcelona, 1983, pp. 301302.

${ }^{44}$ Así, su esposa era sobrina por línea materna de Anton Serra i Portell, oidor de la Sala Civil de la Audiencia de Cataluña; cuñada de Ramon Ferran i Biosca, con análago cargo; y prima hermana de la esposa de Antoni Güell i Trelles, regidor del ayuntamiento de Barcelona; además de estar emparentada con los Prous, también vinculados al gobierno municipal de la ciudad. (P. Molas i Ribalta, "Catalans a l'administració central al segle xVIII’, Pedralbes, núm. 8-11 (1988), pp. 181-188).

${ }^{45}$ En el inventario post mortern de Josep Duran i Mora aparecen interesantes noticias sobre sus negocios. Sabemos, por ejemplo, que la sociedad Jusep y Jaume Duran era heredera de la de Joseph y Vicenç Duran constituida en 16.95, sociedad que fue renovándose periódicamente. Entre los años 1728 y 1732, la razón social Josep y Jaume Duran integraba a Josep Duran i Mora, con un capital social de 60.000 libras; a su hijo primogénito, Jaume Duran i Pujades, que era el administrador de la compañía; a Pere Duran i Isern, hijo del anterior y nieto de Josep Duran; a Josep Duran i Sala, hijo de Vicenç Duran i Mora y, más tarde, regidor del ayuntamiento de Barcelona; a Pere Pau Vilella, casado con Maria Duran Quatrecases, sobrina de Josep Duran i Mora. Finalmente, completa la masa social Jeroni Duran i Alamany, también sobrino de Josep Duran, que más tarde será comerciante matriculado de la Junta de Comercio de Barcelona en 1758. Esta compañía se renovó, que se sepa, por otro quinquenio, es decir hasta 1737 , fecha en que ya había muerto Josep Duran i Mora, por lo que le sucedería como heredero su hijo mayor habido de su segundo matrimonio, Domènec Duran i Muxica. 
estudiada por Roberto Fernández, podrían situarse en la cúspide de los grandes comerciantes del siglo XVIII, incluso por encima de la familia Milans, por lo menos en la primera mitad de la centuria ${ }^{47}$.

Tal ennoblecimiento de la familia Duran no le impidió participar en las empresas más dinámicas del periodo borbónico, siendo Jaume Duran i Pujades pionero en la tentativa de constituir una Junta de Comercio en 1732, convirtiéndose en su director, proyecto cuyas vicisitudes y fracaso final han sido suficientemente estudiados por Pere Molas ${ }^{48}$. La iniciativa encontrará recompensa en 1758, cuando el hermano del anterior, Domènec Duran i Muxica, señor de Ribelles, donzell y, finalmente, noble en 1746, aparezca como comerciante matriculado en la recién estrenada institución de la Junta de Barcelona. Su hijo, Antoni Duran i Bastero, también comerciante matriculado, abandonará los negocios en 1781 para dedicarse a sus propiedades agrícolas ${ }^{49}$.

El descendiente de Jaume Duran i Pujades proseguirá un camino distinto. Así, Pere Duran i Isern, donzell, sabrá aprovechar la herencia de los Pujadas de Sabadell, heredada por su padre, para invertir en la manufactura textil. De ahi que aproveche sus contactos en la zona para establecer, en 1747, una fábrica de paños, cuyo destino será el mercado interior peninsular, lo que evidencia el trasva-

46 J. M. Torras i Ribé: Els municipis..., p. 262

47 R. Fernández Diaz establece una jerarquía entre los diferentes comerciantes de la Barcelona del siglo XVII!, utilizando su aportación al ganancial como indicador del volumen de negocio generado. Sus resultados le llevan a afirmar que la sociedad Milans, analizada entre 1724 y 1797, constituyó la mayor compañía mercantil de la centuria. (R. Fernández Díaz, La burguesía comercial barcelonesa en el siglo XVIII, tesis doctoral inédita, Lérida, 1988, v. II, pp. 533-539). Sin embargo, creemos poder afirmar que fue la sociedad Josep, Vicenç, Jaume, Domènec y Jeroni Duran la que debió ocupar ese primer lugar ya que, si sumamos la aportación al ganancial de la compañía Josep y Jaume Duran (1724-1770) y la constituida por Domènec y Jeroni (1736-1770), el conjunto familiar queda muy próximo a los Milans. Por otro lado, las fuentes fiscales utilizadas son muy limitadas, ya que no permiten detectar las inversiones realizadas por la compañía Duran en otras sociedades, deficiencia que se ha suplido con la consulta de la documentación notarial, la cual revela la participación de la firma Duran en otras sociedades mercantiles. Así, si tenemos en cuenta otras compañías integradas en los negocios de los Duran, seguramente podríamos situar a la familia en la cúspide de la burguesía mercantil barcelonesa. Esta hipótesis puede ser verificada en las primeras décadas del siglo xVIII, ya que, como ya señalamos, la sociedad Josep y Jaume Duran fue, por lo menos hasta los años treinta, la única firma que emitió letras en la plaza de Barcelona. También cabe destacar la importancia de las relaciones de parentesco para identificar los diferentes socios que integraron la masa social de la compañia Duran, método que nos ha permitido detectar otras inversiones de la misma firma en otras sociedades, como la creada para regentar la droguería familiar de los Duran, situada en la plaza del Born, que ya se hallaba bajo la administración de Francesc $\mathrm{Pla}$, adroguer, y que iniciada en 1711 permariecía activa en 1733; compañia en la que Josep Duran i Mora habia invertido 7.000 libras y en la que también participó su hijo Jaume y su sobrino Josep Duran i Sala. Su administrador Josep Pla era un pariente próximo, ya que había contraido matrimonio con Maria Paula Duran i Alemany, quien, a su muerte, nombrará heredero universal de sus bienes a su hermano Jeroni Duran i Alemany, comerciante matriculado en 1758 y socio de su primo hermano, Doménech Duran i Muxica, hijo del segundo matrimonio del conocido mercader Josep Duran i Mora, también comerciante matriculado el mismo año. (AHPB. Not. Pau Mollar, De inventariis et actionibus, Inventario de Josep Duran i Mora, 19 de septiembre de 1735, s.f. La familia Duran también tenía participación en la compañía de Pere y Josep Vilella (AHPB. Not. Antoni Duran Quatrecases, 20 Liber Inventariorum et encantorum (1749-1758). Inventario del 1 de marzo de 1751, fols. 26-34).

48 P. Molas i Ribalta, Comerc...., pp. 212-213.

${ }^{49}$ P. Vilar: Catalunya..., v. III, p. 284. 
se de los beneficios del capital mercantil y su inversión en el sector manufacturero ${ }^{50}$.

La siguiente generación estuvo representada por Francesc Duran i Puig, que será director de la Junta de Comercio de Barcelona ${ }^{51}$. Finalmente, Enric Duran i Duran, la última generación documentada, será alcalde de Barcelona en 1879-188152.

La actitud política de la familia Duran a lo largo del período estudiado, así como las estrategias comerciales emprendidas en su ascenso social, pueden servirnos para extrapolar el comportamiento de amplios sectores de la burguesía mercantil de Barcelona, antes y después de la Guerra de Sucesión, pero también de otros sectores sociales más amplios, con los que estuvieron relacionados, los cuales se integraron, asimismo, en la causa aliada.

Los datos expuestos son suficientes para perfilar la red de intereses que condujo a la burguesía mercantil barcelonesa a constituirse en la savia del partido austracista, incluso a conspirar para propiciar el giro dinástico, aunque los escasos signatarios del pacto de Génova no permitan corroborar su implicación.

Por ello, creemos que dentro de la burguesia mercantil, los sectores más interesados en el giro dinástico estarían constituidos por aquellas familias relacionadas con aquellas casas comerciales vinculadas con el comercio atlántico que se habian concentrado en Barcelona, así como en las localidades marítimas del Maresme, cuyo epicentro sería Mataró, sin olvidar el área de influencia en torno al puerto de Salou.

Sin duda, uno de los ejes básicos de ese comercio fue el integrado por ReusSalou, especializado en la exportación de aguardiente del Baix Camp de Tarragona, cuya producción estuvo supeditada y conirolada por las firmas comerciales de Barcelona.

La burguesía mercantil austracista también estuvo integrada por las familias que se habian beneficiado de la extensión de los viñedos del Maresme, una de las áreas comerciales más dinámicas desde finales del siglo xVII, cuyo centro, la villa de Mataró, llegó a rivalizar con Barcelona. Sin embargo, el traslado de muchos comerciantes de Mataró a la ciudad condal, asi como el mantenimiento y compra de propiedades (casa y viñedos) en los lugares de origen, tal vez permitió compatibilizar los intereses de la burguesía mercantil en ambas localidades, la mayor parte de las veces reforzados por las relaciones de parentesco entre sus diferentes ramas.

Dentro de los grupos vincuiados al comercio atlántico, vemos a los adroguers de Barcelona y Mataró, especialmente interesados en la importación de coloniales

50 AHPB. Not. Anton Duran Quatrecases, Primus liber concordiarum, 1732-1748, fols. 157-159. Se asociará con Joan Amat i Salvany, payés de Sabadell, quien actuará como administrador, sin aportación de capital. Joan Amat fue regidor de Sabadell en 1721. (N. Domènec y M. M. Rios, El municipi de Sabadell a l' Edat Moderna. Terrasa, 1988, p. 55). También se dedicará a otro tipo de negocios, pues en un inventario de 1751 figuraban remesas de mercancías a Veracruz. (C. Martinez Shaw, Cataluña..., p. 69).

51 C. Martínez Shaw, Cataluña..., p. 69.

52 Diccionari d' Història de Catalunya, Barcelona, 1999, p. 36.9. 
desde Lisboa. Es evidente que dentro de este grupo aparecieron importantes austracistas como los mismos hermanos Duran, pero también los Dalmau, los Mascaró, los Colomer, todos ellos de Barcelona, o Marià Pujol de Mataró.

La firma Vicenç y Josep Duran encarna el ascenso social de la élite gremial, los adroguers, al mundo del gran comercio, gracias a la coyuntura alcista del último cuarto del siglo XVII. Lo que les llevó a orientar su actividad progresivamente hacia los mercados del Atlántico Norte; negocio que se completó con la importación de coloniales desde Lisboa para su droguería.

Asimismo, engrosaron las filas del partido austracista los grupos interesados en la recuperación de la tradicional pañería catalana, como Narcís Feliu de la Penya, a través de sus contactos con hombres de la Plana de Vic, pero también algunos hombres de las localidades donde esta actividad era prioritaria, por lo que no es extraño que pudieran ver, en una alianza con los Austrias, un contrapeso a la competencia económica que suponían los paños franceses. De ahi que algunos de estos centros apoyen decididamente al Archiduque, e incluso que algunas familias de origen paraire, como los Parrella de Torelló o los Bricfeus i Guàrdia de Castellterçol, se conviertan en fervorosos defensores de la causa austracista, obteniendo del nuevo régimen cargos y honores ${ }^{53}$.

Finalmente, entre los defensores de las constituciones catalanas aparece un grupo de juristas e historiadores, muchos de ellos pertenecientes a importantes familias comerciantes, que, sin abandonar sus relaciones comerciales, han logrado ingresar en las filas de la ciudadanía honrada o de la pequeña nobleza. El más conocido es, sin duda, Narcís Feliu de la Penya, pero tampoco debemos olvidar a Pau Ignasi de Dalmases i Ros, embajador plenipotenciario en Inglaterra al final de la guerra, ligado a una de las firmas comerciales más importantes de la ciudad. No obstante, otros personajes han pasado más desapercibidos, como Francesc Toda i Gil, hijo de un fabricante de aguardiente de Riudoms, que ingresaria en el Consejo del Reino creado por Carlos $\mathrm{II}^{54}$, donde aparecen hombres con un origen social semejante, como Fortià Parrella, perteneciente a una familia originaria de Torelló emparentada con los Feliu de la Penya y los Duran. Por último, Francesc Grases i Gralla, el denostado autor del Epítome, acusado durante el periodo austracista de atentar contra las Constituciones de Cataluña, de ahí que no podamos incluirlo dentro del grupo anterior aunque presente un perfil social y una trayectoria similar a la de los personajes citados. Pertenecía a una familia de la burguesía mercantil que había conseguido ingresar en el máximo órgano judicial del Principado. El polémico jurista era hermano de Josep Grases de Reus, un importante propietario de viñedos, interesado en los negocios de barcos de Mataró

53 Jacint Pineda i Guàrdia y Jaume Bricfeus i Tern, ambos paraires de Castellterçol, obtuvieron sendos títulos de ciudadanos honrados por parte del Archiduque. Títulos que, por otra parte, se mantuvieron tras la represión borbónica. (Cf. M. Bruguera, Sitio..., vol. Il, pp. 464-470).

${ }^{54}$ Sobre la trayectoria juridica de Francesc Toda, cf. A. Porta, La victòria..., pp. 292, 571, 585-586. Sus vínculos familiares con la fabricación de aguardiente, en C. Martínez Shaw, Cataluña..., pp. 50-51, 84 y 205. 
y socio del comerciante Salvador Feliu de la Penya en la Companyia Nova de Gibraltar ${ }^{55}$.

Estos ejemplos ilustran la tupida red que la burguesia comercial había tejido hasta imbricarse en todas las instituciones catalanas. Una red creada a partir de complejas relaciones de parentesco, que juegan un papel de primer orden en la configuración de la oligarquía urbana de Barcelona y en la que confluirán familias procedentes de las localidades económicamente más dinámicas de la Cataluña del último cuarto de siglo XVII.

Las redes comerciales que unirán las diferentes localidades implicadas en la recuperación económica de la Cataluña de la década de 1680 , no sólo prefiguran la geografía de los primeros focos austracistas, como demuestran los negocios de la firma Duran, sino que reproducen los intereses de las sociedades mercantiles más importantes de Barcelona, pero también la estrategia matrimonial de muchas de estas familias, quienes no sólo practican la diversificación del riesgo para invertir sus caudales, sino que, mediante el establecimiento de convenientes matrimonios, controlan un radio geográfico muy amplio, que abarcará los núcleos más prósperos de la Cataluña de finales del siglo XVII. Unos lazos de parentesco necesarios para el desarrollo de unos intercambios comerciales apoyados en la descentralización económica y que marcarán la recuperación catalana de la época. De todo ello, se deduce que la estrategia matrimonial de la burguesía mercantil barcelonesa, tanto de los Duran, como de los Feliu de la Penya, más conocida, fue más allá de la pura endogamia grupal y permitió, mediante la unión de algunos de sus miembros con familias enriquecidas de otros núcleos catalanes, una inversión con posibilidades, una reciprocidad generalizada, que se tradujo en nuevos mercados, aprovechando las redes sociales de los nuevos parientes, es decir, nuevas expectativas para negociar y lucrarse. Una perfecta simbiosis que logró convertir un proyecto económico, el de la burguesía mercantil barcelonesa, pero también de los grupos sociales relacionados con ella, en un proyecto político, encarnado por la monarquía de Carlos III.

La rápida integración de los Duran en la maquinaria borbónica puede explicarse por ese deseo de negociar y lucrarse, deseo que se materiaiizó en una impresionante participación de la firma comercial en los negocios creados por los vencedores contra quienes habian luchado. Entre ellos cabe destacar el suministro de víveres a un ejército que permanecía en el Principado como símbolo de su derrota como grupo social, pero que supuso pingües beneficios a la burguesía comercial de la ciudad, los mismos beneficios que habían generado las campañas bélicas del ejército habsburgués frente a Francia en la centuria anterior, lo que explicaria la adhesión de este sector social a la Monarquía de Carlos II en la revuelta de les barretines, tal como ha señalado Antonio Espino ${ }^{56}$.

${ }_{55}$ P. Anguera, «Sobre Joseph i Francesc Grases i Gralla. Un comerciant i un advocat del segle XVII!», Estudis Històrics i Documents de l' Arxiu de Protocols, Barcelona, 1980, pp. 245-251.

56 A. Espino, “La burguesía catalana y la guerra, 1680-1697», en L. M. Enciso Recio (coord.): La burguesía española en la Edad Moderna, Valladolid,1996, v. Ili, pp. 1.409-1.425. 
Por otro lado, los fondos procedentes del denostado impuesto del catastro, así como otros establecidos por los Borbones (sal, tabaco, papel sellado, etc.), drenados por la Intendencia de Cataluña, aunque insuficientes para mantener al ejército de ocupación, supondrían una inyección de numerario que circulará en el Principado activando su economía y dinamizando especialmente a algunos sectores de la burguesía comercial, que tendrían en la demanda estatal grandes expectativas comerciales. Como fue el caso de la familia Duran ${ }^{57}$.

Su actitud colaboracionista con el nuevo modelo político-administrativo impuesto por los Borbones no fue excepcional, sino que otros muchos comerciantes austracistas acabaron negociando con las nuevas autoridades en el poder. De ahí que no sólo debamos matizar, sino, incluso, poner en duda la tradicional tesis sobre la ruptura generacional de la burguesía mercantil del siglo XVII como consecuencia de la contienda bélica ${ }^{58}$.

Las expectativas comerciales surgidas de la nueva realidad de Cataluña tras la guerra de Sucesión (expectativas que plasmarian viejos sueños de la burguesía mercantil barcelonesa) determinaron, sin duda, el colaboracionismo de muchos antiguos hombres de negocios austracistas en este período de transición. Una transición que debe ser analizada para una mayor comprensión de las raíces de la expansión económica de Cataluña en el siglo XVIII, ya que sin la participación decidida en la nueva coyuntura de hombres como los Duran, cuyos capitales se labraron al amparo de la recuperación económica del Principado a partir de la década de 1680 , y que supieron encauzar su dinamismo empresarial en el nuevo marco político y económico, difícilmente puede entenderse el emprendedor dinamismo del Setecientos.

57 Esta es la tesis de J. Mercader, Felip V..., pp. 193-194. La importancia de la demanda estatal en la economía catalana del siglo XVIII fue destacada por M. Arranz, quien ya cuestionaba la tradicional tesis esbozada por J. Nadal i Farreras sobre la transferencia de recursos de Cataluña hacia el centro del aparato del Estado en el periodo borbónico. Cf. M. Arranz, "Demanda estatal i activitat econòmica sota els primers Borbons (1714-1808), Actes del Primer Congrés d' Història Moderna de Catalunya, v. II, Barcelona, 1984, p. . 259-265. Para la tesis de J. Nadal sobre las consecuencias del sistema impositivo aplicado por los Borbones en la Cataluña del siglo XVIIl, cf. La introducción del catastro en Gerona, Barcelona, 1971.

58 Este trabajo se enmarca dentro de otro más amplio sobre las repercusiones de la Guerra de Sucesión en el mundo del comercio de la Barcelona del siglo xvili, donde verificaremos esta afirmación. 